\title{
40. PISA'nın ışığında geliştirilen ABİDE projesinde okuma bakımından ne hâldeyiz? Bir geçerlilik çalışması
}

\section{Talha GÖKTENTÜRK1}

\section{İbrahim DEMİR²}

\section{Ali Fuat ARICI3}

\begin{abstract}
APA: Göktentürk, T.; Demir, İ.; Arıcı, A. F. (2021). PISA’nın ışığında geliştirilen ABİDE projesinde okuma bakımından ne hâldeyiz? Bir geçerlilik çalışması. RumeliDE Dil ve Edebiyat Araştırmaları Dergisi, (22), 657-665. DOI: 10.29000/rumelide.897081.
\end{abstract}

\section{$\ddot{O} \mathbf{z}$}

Çalışmamızda MEB Ölçme ve Değerlendirme ve Sınav Hizmetleri Genel Müdürlüğünün Veri Analizi, İzleme ve Değerlendirme Daire Başkanlığı birimi ile yapılan yazışmalar neticesinde erişilebilen ABİDE 2016 Türkçe-A testine cevap veren öğrencilerden seçilen 6000 kişilik veri analiz edilmiştir. İlgili kitapçıta araştırmacılara 9 madde verilmiş olup araştırma boyunca ilgili maddelerin hedef kitlenin cinsiyet, kurum türü ve bölge değişkenlerinin alt gruplarında madde yanlılığına işaret eden diferansiyel madde fonksiyonunu gösterip göstermediği incelenmiştir. Parametrik veri setlerine uygunluğu ve maddelere verilen cevapların hiyerarşik yapı içermesi sebebiyle lojistik regresyon analizleri seçilmiştir. Maddelere verilen cevapların ordinal bir yapı içermesi sebebiyle de ordinal lojistik regresyon analizi ana analiz metodu olarak belirlenmiştir. İlgili metot yoluyla yapılan DMF (diferansiyel madde fonksiyonu) analizleri neticesinde madde yanlılığına işaret eden maddeler varsa bulgulaştırılarak raporda sunulmuştur. Elde edilen sonuçlar ABIDE maddelerinin alt gruplara yönelik olarak orta ve yüksek derecede diferansiyel madde fonksiyonuna sahip olmadığına işaret etmektedir. Bulgular ilgili maddelerin analiz edilen alt gruplar için geçerli olduğu şeklinde yorumlanabilir. Bununla beraber mevcut bulguların oluşmasına sebep olabilecek istikşafi analizlerin gelecek araştırmalarda yapılması milli bir izlemedeğerlendirme sisteminin kurulmasında katkı sağlayacaktır. Son olarak ABİDE projesinin PISA (Program for International Student Assessment) gibi açık veri politikası izlemesi ve daha geniş veri paylaşımında bulunması projenin güvenilirliğini de artıracak ve daha derinlikli veri elde edilmesine imkân sağlayacaktır.

Anahtar kelimeler: PISA, ABİDE, diferansiyel madde fonksiyonu, madde yanlılı̆̆ı

Arş. Gör., Yıldız Teknik Üniversitesi, Eğitim Fakültesi, Türkçe ve Sosyal Bilimler Eğitimi Bölümü, Türkçe Eğitimi ABD (İstanbul, Türkiye), talhagoktenturk@gmail.com, ORCID ID: 0000-0002-8619-0698 [Araștırma makalesi, Makale kayıt tarihi: 17.01.2021-kabul tarihi: 07.02.2021; DOI: 10.29000/rumelide.897081]

2 Doç. Dr., Yıldız Teknik Üniversitesi, Fen-Edebiyat Fakültesi, Uygulamalı İstatistik ABD (İstanbul, Türkiye), idemir@gmail.com, ORCID ID: 0000-0002-2734-4116.

3 Prof. Dr., Yıldız Teknik Üniversitesi, Eğitim Fakültesi, Türkçe ve Sosyal Bilimler Eğitimi Bölümü, Türkçe Eğitimi ABD (İstanbul, Türkiye), ariciali-fuat@gmail.com, ORCID ID: 00o0-0002-2734-4116.

Adres | Address 


\title{
Where are we in the reading items of the ABIDE project developed in the light of PISA? A validity study
}

\begin{abstract}
In this research, we used and analyzed the data obtained from Ministry of Education General Directorate of Assessment and Examination Services. Analyzed data consists of ABİDE 2016 Turkish-A booklet, and the data was collected from 6000 participants. We aimed to find out whether the subgroups to which the ABIDE reading test items are applied contain DIF among the gender subgroups. We chose logistic regression analyzes because of their suitability to parametric data sets. Ordinal logistic regression analysis was determined as the main analysis method because the responses given to the items contain an ordinal structure. As a result of the DMF analysis, we did not determine any differential item functioning. The results obtained indicate that ABIDE substances do not have medium and high degree differential item function for subgroups. The findings can be interpreted as the relevant items are valid for analyzed subgroups. However, conducting exploratory analyzes that may lead to the formation of existing findings in future research will contribute to the establishment of a national monitoring-evaluation system. Finally, the fact that the ABIDE project follows an open data policy such as PISA and shares broad data, will increase the reliability of the project and allow more in-depth data to be obtained.
\end{abstract}

Keywords: PISA, ABIDE, differential item functioning, item bias

\section{Giriş}

2001 yllında yenilenen (Anderson ve Krathwohl, 2001) Bloom'un taksonomisinin (Bloom, 1956) ışığında PISA araştırmalarında analiz etme, değerlendirme ve yaratma becerilerinin de ölçüldüğü görülmektedir (Prastiwi, 2017). Yapılan analizler ise ülkemizdeki liselere geçiş imtihanında sadece uygulama ve analiz basamaklarına kadar erişilebildiğini göstermektedir (Ekinci ve Bal, 2019). Dolayısıyla PISA imtihanlarının ölçme alanları kadar zihnî becerilere yönelik geniş bir alanda yazılmayan maddeler öğrencilerimizin ilk defa gördüğü soru tipleri ile karşı karşıya kalmasına sebebiyet vermektedir.

Üst seviye zihnî becerilerin ölçülmesinde karşılaşılan problemler ve açık uçlu sorularla öğrencilerin daha fazla karşılaşmasının bir ihtiyaç olarak görülmesi sonucunda ABİDE (Akademik Becerilerin İzlenmesi ve Değerlendirilmesi) projesi hayata geçirilmiştir (MEB, 2020). Pilot ve esas uygulamalar neticesinde yayımlanan rapor metni ABIDE bulgularının PISA ve TIMSS (Trends in International Mathematics and Science Study) ile örtüştüğünü, yani öğrencilerin eğitimden beklentileri artıkça akademik başarı seviyelerinin de yükseldiği belirlenmiştir (MEB, 2016). Tabakalı örneklemenin (Yıldırım ve Şimşek, 2016) kullanıldı̆̆ öğretim ve son olarak okul türlerine dikkat edildiği görülmektedir (MEB, 2016).

Çalışmamızda tabakalı örneklemeye dâhil edilen gruplar örnekleme sistemi dâhilinde temsil edilirken araştırmanın sınırlılığı ve ekonomikliği prensibi sebebiyle (Creswell, 2017. Fraenkel, Wallen ve Hyun, 2012) tabii olarak her alt grup temsil edilmemiştir. Proje üzerine yapılan farklı çalışmalar da başarı puanlarını etkileyen muhtemel değişkenlerin ehemmiyetine işaret etmektedir (Çalık, 2020). Bu sebeple ABİDE projesi araştırmalarına katkı sağlamak, ayrıca varsa muhtemel madde yanlılıklarını

\begin{tabular}{|c|c|}
\hline & \\
\hline alarn $D$ & d Literatur \\
\hline $\mathrm{Mal}$ & Mahallesi, Mürver Çiçeği Sokak, No:14/8 \\
\hline Kadıköy & STANBUL / TURKEY 34714 \\
\hline $\begin{array}{r}\text { e-posta: edito } \\
\text { tel: }+905057958124,+\end{array}$ & $\begin{array}{l}\text { editor@rumelide.com, } \\
\text { +90 505 7958124, +90 } 216773 \text { o } 616\end{array}$ \\
\hline
\end{tabular}


ortaya koymak amacıyla cinsiyet alt gruplarına yönelik diferansiyel madde fonksiyonlarının belirlenmesine çalışlacaktır.

Bugüne kadar yapılan araştırmalarda farklı gruplarda kız öğrenciler lehine anlamlı sonuçların elde edildiği görülmektedir (Arslan, 2013). Bu farklılık kızların daha başarılı olması olarak yorumlanabileceği gibi eğitim seviyesi yükseldikçe kızların eğitim imkânlarından daha az yararlanması gibi (Sarıer, 2010) cinsiyet eşitsizliğine dayalı sebeplerden de kaynaklanabilir. Bununla beraber kız ve erkekler arasındaki fırsat eşitsizliğine yönelik çalışmalarda anlamlı farklılaşmanın okuma becerisi üzerinde daha slk görüldüğü belirlenmiştir (Ferreira ve Gignoux, 2010). Bu konuda madde yanlılı̆̆na yönelik çalışmalar ise kız ve erkek grupları arasında oluşan madde yanlılığının cinsiyet eşitliği indeksi ile beraber analiz edildiğinde ortadan kalktığı yönündedir (Chen ve Zumbo, 2017). Cinsiyetin yanında okuma becerisinin farklı değişkenlerden de etkilenebileceği öngörülmekte ve bu doğrultuda okul çevresinin düzenlenmesi de tavsiye edilmektedir (Batur ve Alevli, 2014). Bu sonuçlardan hareketle ABIDE verileri için de cinsiyet, kurum türü ve bölge değişkenlerinin alt grupları için muhtemel yanlılıkların diferansiyel madde fonksiyonu analizleri ile incelenmesi araştırmanın ana çerçevesini oluşturmaktadır.

\section{Araştırmanın metodu ve problemi}

Bir araştırma evrenini oluşturan değişkenler arasındaki ilişkinin araştıılması sebebiyle korelasyonel araştırma (Fraenkel, Wallen ve Hyun, 2012) olarak çalışma tasarlanmıştır. Bu çerçevede araştırmanın amacı ise şu şekilde ifade edilebilir:

1. ABİDE okuma testi maddelerinde cinsiyet alt gruplarına yönelik diferansiyel madde fonksiyonu mevcut mudur?

2. ABIDE okuma testi maddelerinde kurum türü alt gruplarına yönelik diferansiyel madde fonksiyonu mevcut mudur?

3. ABIDE okuma testi maddelerinde bölge alt gruplarına yönelik diferansiyel madde fonksiyonu mevcut mudur?

\section{Verilerin analizi}

Diferansiyel madde fonksiyonu analizleri belirli bir testi alan alt gruplardan birine ve birkaçına haksız avantaj sağlayıp sağlamadığının belirlenmesi amacıyla yapılmaktadır (Özbek, 2014). Araştırma sürecinde verilerin analizinde lojistik regresyon analizlerinin parametrik veri setlerine uygunluğu (Swaminathan \& Rogers, 1990) sebebiyle kullanılması kararlaştıılmıştır. Verilerin hiyerarşik bir yapı içermesi sebebiyle de ordinal lojistik regresyon analizlerinin kullanılabileceği öngörülmüştür (Zumbo, 1999). Zumbo'nun (1999) teklifi doğrultusunda analiz aşamaları şu şekilde planlanmıştır:

1. Birinci aşamada testin maddeleri ile test maddelerinin toplam puanı arasındaki regresyon incelenmiştir.

2. İkinci aşamada grup değişkeni olan cinsiyet faktör olarak analiz sürecine dâhil edilmiştir. Kovaryans değeri olarak yine toplam puan analiz sürecindedir. Son olarak bağımlı değişken olarak maddenin kendisi analiz sürecinde incelenmiştir.

3. Son aşamada ise cinsiyet ve ünitenin toplam puanlarının kesişimi sürece dâhil edilmiş ve kurulan denklem tamamlanmıştır. Analiz sonucunda ise DMF'nin seviyesinin belirlenmesi için üçüncü adımda elde edilen ki kare ve Negalkerke $\mathrm{R}^{2}$ değerleri birinci adımda elde edilen değerlerden çıkarılmıştır.

\footnotetext{
Adres $\mid$ Address

RumeliDE Dil ve Edebiyat Araştırmaları Dergisi $\quad$ RumeliDE Journal of Language and Literature Studies

Osmanağa Mahallesi, Mürver Çiçeği Sokak, No:14/8 Osmanağa Mahallesi, Mürver Çiçeği Sokak, No:14/8

Kadıköy - İSTANBUL / TÜRKIYE 34714 Kadıköy - ISTANBUL / TURKEY 34714

e-posta: editor@rumelide.com e-mail: editor@rumelide.com,

tel: +90 505 7958124, +90 2167730616 phone: +90 505 7958124, +902167730616
} 
Where are we in the reading items of the ABIDE project developed in the light of PISA? A validity study / T. Göktentürk; $\dot{\mathrm{I}}$. Demir; A. F. Arıcı (pp. 657-665)

Negalkerke R2 "R2 <,035 ise DMF yoktur ya da ihmal edilebilir seviyedir (A), o,035 $\leq \mathrm{R} 2<$ o, 070 ise orta seviyede DMF vardır (B), R2 $\geq 0,070$ ise mühim seviyede DMF vardır (C)." şeklinde sınıflanmıştır (Jodoin \& Gierl, 2001). Verilerin analize hazırlanması sürecinde ise örneklem ağırlıklandırması kullanılmıştır. MEB’in (2016) örgün eğitim istatistiklerine göre 2015-2016 eğitim-öğretim yılında Türkiye'de 8. sınıfı bitiren öğrenci sayısı 1.366.138'dir. Bu veriden hareketle örneklem olarak araştırmacılara ulaştırılan 6002 katılımcının değeri de hesaba katılmıştır. Böylece kullanılan örneklem ağırlıklandırması şu formül ile ifade edilebilir (OECD, 2009: 49-50): ÖA=1/(n/N).

\section{Bulgular}

MEB Ölçme ve Değerlendirme ve Sınav Hizmetleri Genel Müdürlüğünün Veri Analizi, İzleme ve Değerlendirme Daire Başkanlığı birimi ile yapılan yazışmalar neticesinde 9 maddelik ABİDE 2016 Türkçe-A testi verileri analiz edilmiştir. Her maddenin analizi ayrı ayrı yapılarak tablo hâlinde sunulmuştur.

1. Tablo: Cinsiyet değişkeni alt gruplarına yönelik DMF analizi sonuçları

\begin{tabular}{|c|c|c|c|c|c|}
\hline \multirow{2}{*}{ Madde } & \multicolumn{2}{|l|}{ DMF } & \multirow{2}{*}{$\frac{\mathrm{DMF}}{\Delta \mathbf{R}^{\mathbf{2}}}$} & \multirow{2}{*}{ DMF Türü } & \multirow{2}{*}{ DMF Seviyesi } \\
\hline & $\mathbf{x}^{2}$ & $\mathbf{p}$ & & & \\
\hline 1. Madde & 57,606 & , ooo & , ooo & A & İhmal edilebilir. \\
\hline 2. Madde & 3092,207 & ,000 & ,002 & A & İhmal edilebilir. \\
\hline 3. Madde & 6014,428 & , OOO & ,005 & A & İhmal edilebilir. \\
\hline 4. Madde & 252,381 & , OOO & ,ooo & A & İhmal edilebilir. \\
\hline 5. Madde & 1772,987 & , 000 & ,001 & A & İhmal edilebilir. \\
\hline 6. Madde & 4912,017 & , 000 & ,004 & A & İhmal edilebilir. \\
\hline 7. Madde & 821,612 & ,000 & ,001 & A & İhmal edilebilir. \\
\hline 8. Madde & 7546,993 & , 000 &, 007 & A & İhmal edilebilir. \\
\hline 9. Madde & 1449,361 & , 000 & ,001 & A & İhmal edilebilir. \\
\hline
\end{tabular}


İlgili sonuçlar cinsiyet değişkeni alt gruplarında diferansiyel madde fonksiyonu oluşmadı̆̆ı yönündedir.

2. Tablo: Kurum türü değişkeni alt gruplarına yönelik DMF analizi sonuçları

\begin{tabular}{|c|c|c|c|c|c|}
\hline \multirow{2}{*}{ Madde } & \multicolumn{2}{|l|}{$\mathrm{DMF}$} & \multirow{2}{*}{$\begin{array}{c}\mathrm{DMF} \\
\Delta \mathbf{R}^{\mathbf{2}}\end{array}$} & \multirow{2}{*}{ DMF Türü } & \multirow{2}{*}{ DMF Seviyesi } \\
\hline & $\mathbf{x}^{2}$ & $\mathbf{p}$ & & & \\
\hline 1. Madde & 2170,435 & ,oo0 & ,002 & A & İhmal edilebilir. \\
\hline 2. Madde & 3502,953 & ,000 & ,002 & A & İhmal edilebilir. \\
\hline 3. Madde & 2244,441 & ,000 & ,002 & A & İhmal edilebilir. \\
\hline 4. Madde & $2.237,41$ & ,000 & ,001 & A & İhmal edilebilir. \\
\hline 5. Madde & $2.237,41$ & ,000 & ,002 & A & İhmal edilebilir. \\
\hline 6. Madde & $1.927,362$ & ,oOO & ,001 & A & İhmal edilebilir. \\
\hline 7. Madde & $1.927,362$ & ,oO0 & ,003 & A & İhmal edilebilir. \\
\hline 8. Madde & $1.927,362$ & ,000 & ,004 & A & İhmal edilebilir. \\
\hline 9. Madde & $1.927,362$ & ,ooo & ,004 & A & İhmal edilebilir. \\
\hline
\end{tabular}

İlgili sonuçlar kurum türü değişkeni alt gruplarında diferansiyel madde fonksiyonu oluşmadı̆̆ı yönündedir.

3. Tablo: Bölge değişkeni alt gruplarına yönelik DMF analizi sonuçları

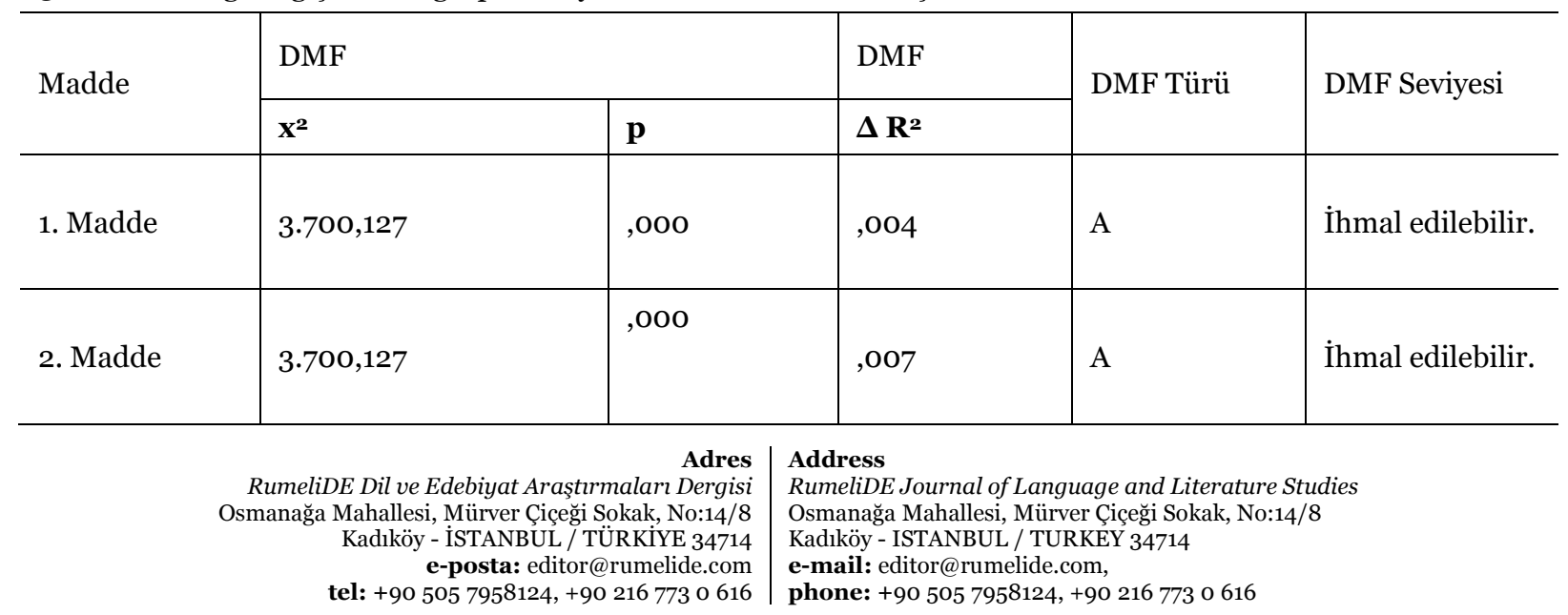


662 / RumeliDE Journal of Language and Literature Studies 2021.22 (March)

Where are we in the reading items of the ABIDE project developed in the light of PISA? A validity study / T. Göktentürk; $\dot{\mathrm{I}}$. Demir; A. F. Arıcı (pp. 657-665)

\begin{tabular}{l|l|l|l|l|l}
\hline 3. Madde & $3.700,127$ &, 000 &, 004 & $\mathrm{~A}$ & İhmal edilebilir. \\
\hline 4. Madde & $3.700,127$ &, 000 &, 004 & $\mathrm{~A}$ & İhmal edilebilir. \\
\hline 5. Madde & $3.700,127$ &, 000 &, 004 & $\mathrm{~A}$ & İhmal edilebilir. \\
\hline 6. Madde & $3.700,127$ &, 000 &, 003 & $\mathrm{~A}$ & İhmal edilebilir. \\
\hline 7. Madde & $4.066,176$ &, 000 &, 003 & $\mathrm{~A}$ & İhmal edilebilir. \\
\hline 8. Madde & $5.063,312$ &, 000 &, 005 & $\mathrm{~A}$ & İhmal edilebilir. \\
\hline 9. Madde & $5.063,312$ &, 000 &, 007 & $\mathrm{~A}$ & İhmal edilebilir. \\
\hline
\end{tabular}

İlgili sonuçlar bölge değişkeni alt gruplarında diferansiyel madde fonksiyonu oluşmadığı yönündedir.

\section{Sonuçlar}

MEB Ölçme ve Değerlendirme ve Sinav Hizmetleri Genel Müdürlüğünün Veri Analizi, İzleme ve Değerlendirme Daire Başkanlığı birimi ile yapılan yazışmalar neticesinde erişilebilen ABİDE 2016 Türkçe-A testine cevap veren öğrencilerden seçilen 6000 kişilik verinin analizi sonucunda okuma testine ait olduğu belirtilen 9 maddenin diferansiyel madde fonksiyonu seviyesi ihmal edilebilir noktadadır. Bu bakımdan maddelerin ilgili alt gruplar bakımından madde yanlılığı içermediği söylenebilir. Bu doğrultuda ABIDEE imtihanları için analiz edilen maddelerin de hedef kitlelere uygulanmasında belirtilen alt gruplar için muhtemel bir madde yanlılı̆̆ öngörülmemektedir.

\section{Tartışma}

Türkiye'de ortaöğretim kurumları imtihanına yönelik yapılan çalışmalarda DMF içeren maddelere rastlandığı belirlenmiştir (Yurdugül ve Aşkar, 2004). TIMSS için de yapılan analizlerde DMF içeren maddelere rastladığı görülmektedir (Şentürk, 2019). PISA üzerine yapılan araştırmalarda ülke, dil ve cinsiyet gibi değişkenlerin alt grupları içinde de DMF tespit edilmiştir (Le, 2009). Mevcut DMF sonuçlarının maddenin etkisinden mi madde yanlılığından $\mathrm{ml}$ yoksa dış değişkenlerden mi kaynaklandığı hususunda da daha detaylı araştırmalara gerek duyulmaktadır (Yurdagül ve Aşkar, 2004). Paralel bir şekilde 3. Nesil DMF araştırmalarında ekolojik arka plana odaklanıldığı bir döneme geçildiği görülmektedir (Zumbo, 2007). Bu sebeple ABİDE projesinden elde edilen 9 madde ve 3 değişkenle yapılan analizlerin projenin 2016 uygulamasındaki maddelerin geçerli olduğunu söylemek için yetersiz olduğu söylenebilir.

\footnotetext{
Adres | Address

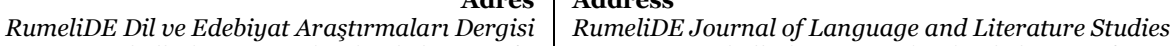
Osmanağa Mahallesi, Mürver Çiçeği Sokak, No:14/8 Osmanağa Mahallesi, Mürver Çiçeği Sokak, No:14/8

Kadıköy - İSTANBUL / TÜRKIYE 34714 Kadıköy - ISTANBUL / TURKEY 34714 e-posta: editor@rumelide.com e-mail: editor@rumelide.com,

tel: +90 505 7958124, +90 2167730616 phone: +90 505 7958124, +90 2167730616
} 
Cinsiyet değişkeni üzerine yapılan araştırmalara bakıldığında PISA'nın 2018'e ait Türkiye sonuçları okuma becerilerinde kızların daha başarılı olduğuna işaret etmektedir (Suna ve diğerleri, 2019). Mevcut farklılıklar, her ne kadar etki olarak yorumlanamasa da değişkenin ölçme maddelerinin geçerliliğini etkileyebilecek bir faktör olarak görülmesi mümkündür. ABİDE maddelerinde diferansiyel madde fonksiyonu sonuçlarının ihmal edilebilir çıkması imtihanın geçerliliği bakımdan pozitif bir sonuçtur.

ABİDE projesinin hazırlanmasında etkili olan PISA araştırmalarına bakıldığında sosyo-ekonomik düzeyi yüksek olmasının, sınıf ortamının disiplinli olmasının, öğrenci merkezli sınıflarda öğrenim görmenin, anlama hatırlama stratejisini kullanmanın bireylerin okuma başarılarını arttırdı $\breve{g}$ tespit edilmiştir (Güzle Kayır, 2012). İlgili değişkenler Zumbo ve diğerlerinin (2015) geliştirdiği model bakımından düşünüldüğünde okul çevresi ve bölge dâhilinde diferansiyel madde fonksiyonunun muhtemel tetikleyicileri arasındadır. Analiz edilen maddelerde DMF tespit edilmemiş olması bu bakımdan ABİDE projesi için pozitif bir adım olarak değerlendirilebilir.

\section{Sonuçların sınırlılığı ile gelecek araştırmalar için tavsiye ve teklifler}

ABİDE projesi için yapılan analizlerin sonuçları her ne kadar pozitif yönde olsa da kurum tarafından araştırmaya sağlanan veriler 3 bağımsız değişken ile sınırlıdır. Ayrıca muhtemel bir diferansiyel madde fonksiyonu sonucu çıkması hâlinde DMF’nin ortaya çımasını etkileyebilecek değişkenler araştırmamıza dâhil edilememiştir. PISA araştırmaları aynı zamanda şeffaf olması ile de araştırmacılara mühim kolaylıklar sağlamaktadır. ${ }^{4}$ ABİDE verilerinde ise araştırmacıların verilere erişmesi için bürokratik izin süreçlerini yerine getirmesi gerekmektedir. Verilerin şeffaf bir şekilde araştırmacılara örneklemin tamamı ile açılması gelecekteki ABİDE ürünlerinin daha güvenilir bir yapıya bürünmesine katkı sağlayacaktır.

Bununla birlikte ABİDE maddelerinin ölçmeyi amaçladığı bütün alanlardaki maddelerinin diferansiyel madde fonksiyonu analizlerine tabi tutulması geçerlilik analizleri başlığında projenin daha güvenilir olmasını sağlayacaktır. Zumbo ve diğerleri (2015) tarafından geliştirilen ekolojik model gibi çalışmalar derinlikli bakış açısının ve maddelerin arka planındaki değişkenlerin geçerlilik üzerindeki etkisine vurgu yapmaktadır. Bu sebeple ABIDE verileri için araştırmacılara daha fazla firsat verilerek bütünlüklü bir tablo ortaya koymalarına müsaade edilmelidir.

\section{Kaynakça}

Anderson, L. W., \& Bloom, B. S. (2001). A taxonomy for learning, teaching, and assessing: A revision of Bloom's taxonomy of educational objectives. Longman.

Arslan, A. (2013). Okuma becerisi ile ilgili makalelerde cinsiyet değişkeni. Uluslararası Türkçe Edebiyat Kültür Eğitim (TEKE) Dergisi, 2(2), 251-265.

Batur, Z., \& Alevli, O. (2014). Okuma becerileri dersinin PISA okuduğunu anlama yeterlilikleri açısından incelenmesi. Okuma Yazma Eğitimi Araşstırmaları, 2(1), 22-30.

Bloom, B. S., Engelhart, M. D., Furst, E. J., Hili, W. H., \& Krathwohl, D. R. (1956). Taxonomy of educational objectives: Handbook I: Cognitive domain. David McKay.

Chen, M. Y., \& Zumbo, B. D. (2017). Ecological framework of item responding as validity evidence: An application of multilevel DIF modeling using PISA data. B. D. Zumbo, ve A. Hubley, (Ed.). Understanding and investigating response processes in validation research içinde (s. 53-68). Cham, Springer.

4. PISA verilerinin erişilebileceği bağlantı adresi için bakınız: http://www.oecd.org/pisa/data/, 2020 Ocak 17 Pazar. Adres $\mid$ Address

RumeliDE Dil ve Edebiyat Araştırmaları Dergisi $\quad$ RumeliDE Journal of Language and Literature Studies Osmanağa Mahallesi, Mürver Çiçeği Sokak, No:14/8 Osmanağa Mahallesi, Mürver Çiçeği Sokak, No:14/8 Kadıköy - İSTANBUL / TÜRKIYE 34714 Kadıköy - ISTANBUL / TURKEY 34714 e-posta: editor@rumelide.com e-mail: editor@rumelide.com tel: +90 505 7958124, +90 2167730616 phone: +90 505 7958124, +90 2167730616 
Where are we in the reading items of the ABIDE project developed in the light of PISA? A validity study / T. Göktentürk; $\dot{\mathrm{I}}$. Demir; A. F. Arıcı (pp. 657-665)

Creswell, J. W., \& Creswell, J. D. (2017). Research design: Qualitative, quantitative, and mixed methods approaches. Sage Publications.

Çalık, G. (2020). Investıgatıon of 8th grade students' science achievement in Turkey: Results from monitoring and evaluating academic skills study (ABIDDE) 2016 (Tez no: 608197) [Doktora tezi, Orta Doğu Teknik Üniversitesi]. YÖK Tez Merkezi.

Ekinci, O., \& Bal, A. P. (2019). 2018 Yılı Liseye Geçiş Sınavı (LGS) Matematik Sorularının Öğrenme Alanları ve Yenilenmiş Bloom Taksonomisi Bağlamında Değerlendirilmesi. Anemon Muş Alparslan Üniversitesi Sosyal Bilimler Dergisi, 7(3), 9-18.

Ferreira, F. H., \& Gignoux, J. (2010). Eğitimde firsat eşitsizliği: Türkiye örneği. TC Cumhuriyeti DPT ve Dünya Bankası Refah ve Sosyal Politika Analitik Çalışma Programı. Çalsşma Raporu, 4.

Fraenkel, J. R., Wallen, N. E., \& Hyun, H. H. (2011). How to design and evaluate research in education (7. bs.). McGraw-Hill.

Güzle Kayır, Ç. (2012). PISA 2009-türkiye verilerine dayanarak okuma becerileri alanında başarılı okullar ile başarısız okulları ayırt eden okul içi etmenler ve sosyo-ekonomik faktörler (Tez no: 325161) [Yüksek Lisans Tezi, Akdeniz Üniversitesi]. YÖK Tez Merkezi.

Jodoin, M. G., \& Gierl, M. J. (2001). Evaluating type I error and power rates using an effect size measure with the logistic regression procedure for DIF detection. Applied measurement in education, 14(4), 329-349.

Le, L. T. (2009). Investigating gender differential item functioning across countries and test languages for PISA science items. International Journal of Testing, 9(2), 122-133.

Milli Eğitim Bakanlığı. (2020, Ocak 15). Akademik Becerilerin İzlenmesi ve Değerlendirilmesi içinde. http://abide.meb.gov.tr/index.asp

OECD. (2020). Programme for International Student Assesment içinde. http://www.oecd.org/pisa/data/

Milli Eğitim Bakanlığı. (2016). Akademik becerilerin izlenmesi ve değerlendirilmesi (8. Sinıflar raporu). Ölçme, Değerlendirme ve Sinav Hizmetleri Genel Müdürlüğü.

Milli Eğitim Bakanlığı. (2016). Milli Eğitim İstatistikleri Örgün Eğitim 2015/'16. T.C. Milli Eğitim Bakanlığı Strateji Geliştirme Başkanlığı.

OECD (2009). PISA Data Analysis Manual: SPSS (2. bs.). OECD Yayınları. https://doi.org/10.1787/9789264056275-en.

Özbek, Ö. (2014). Diferansiyel Madde Fonksiyonuna Genel Bir Bakış. Sakarya Üniversitesi Eğitim Fakültesi Dergisi, (9), 86-96.

Prastiwi, M. S. (2017). Cognitive Process Analysis of PISA, TIMSS, and UN Science Items Based on Revised Bloom Taxonomy. Advanced Science Letters, 23(12), 12068-12072.

Sarier, Y. (2010). Ortaöğretime Giris Sınavları (OKS-SBS) ve PISA Sonuçları Ișı̆̆ında Eğitimde Fırsat Eşitliğinin Değerlendirilmesi. Journal of Kirsehir Education Faculty, 11(3), 107-129.

Suna, H. E., Tanberkan, H., Taş, U. E., Eroğlu, E., \& Altun, Ü. (2019). PISA 2018 Türkiye ön raporu. Milli Eğitim Bakanlı̆̆ı.

Swaminathan, H., \& Rogers, H. J. (1990). Detecting differential item functioning using logistic regression procedures. Journal of Educational measurement, 27(4), 361-370.

Şentürk, T. (2019). TIMSS'de değişen madde fonksiyonu gösteren maddelerin madde özellikleri açısından incelenmesi (Tez no: 583596) [Yüksek lisans tezi, Hacettepe Üniversitesi]. YÖK Tez Merkezi.

Yıldırım, A., \& Şimşek, H. (2016). Sosyal Bilimlerde Nitel Araştırma Yöntemleri (10. bs.). Seçkin.

Yurdugül, H., \& Aşkar, P. (2004). Ortaöğretim kurumları öğrenci seçme ve yerleştirme sınavi'nın, öğrencilerin yerleşim yerlerine göre, diferansiyel madde fonksiyonu açısından incelenmesi. Hacettepe Üniversitesi Eğitim Fakültesi Dergisi, 27(27).

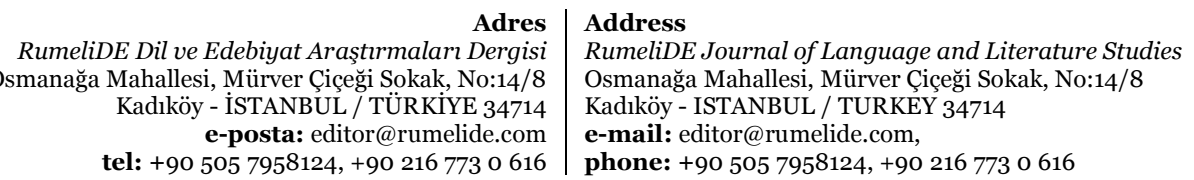


Zumbo, B. D. (1999). A handbook on the theory and methods of differential item functioning (DIF). Ottawa: National Defense Headquarters, 1-57.

Zumbo, B. D. (2007). Three generations of DIF analyses: Considering where it has been, where it is now, and where it is going. Language assessment quarterly, 4(2), 223-233. doi: 10.1080/15434300701375832

Zumbo, B. D., Liu, Y., Wu, A. D., Shear, B. R., Olvera Astivia, O. L., \& Ark, T. K. (2015). A methodology for Zumbo's third generation DIF analyses and the ecology of item responding. Language assessment quarterly, 12(1), 136-151. doi: 10.1080/15434303.2014.972559 